\title{
Pengaruh Product Knowledge, Brand Image, Dan Brand Ambassador Terhadap Keputusan Pembelian Top White Coffe Mahasiswa FEBI IAIN Kudus 2016-2017
}

\author{
Suparwi ${ }^{1}$, Syarifatul Fitriyani ${ }^{2}$ \\ Institut Agama Islam Negeri Kudus ${ }^{12}$ \\ parwiarif@gmail.com ${ }^{1}$, Syarifatulfitri18@gmail.com²
}

\begin{abstract}
This research aims to find the effect of produck knowledge, brand image, brand ambassador against purchasing decisions top white coffie products in students of the faculy of economics and Islamic busines (FEBI) IAIN Kudus 2016-2017. Many factors motivate consumers to make purchasing decisions. Purchasing decisions are consumer behavior in deciding whether to buy a product or not. Usually consuimers will consider before going to decide on a purchase a product that will buy. This research uses quantitative research, the population in this study amounted to 1.091 Student. While the sample used 92 student. The analysis technique uses multiple linear regression analysis. The results of this study indicate that product knowledge has an effect on purchasing decisions. Brand image affects purchasing decisions and brand ambassador influences decision making. And together Product Knowledge, Brand Image, Brand Ambassador influence purchasing decisions.
\end{abstract}

Keywords: Product Knowledge, Brand Image, Brand Ambassador, Buying Decision

Abstrak
Penelitian ini bertujuan untuk mengetahui apakah ada pengaruh Product Knowledge, Brand Image dan Brand Ambassador terhadap Keputusan Pembelian produk Top White Coffie pada mahasiswa FEBI IAIN Kudus 2016-2017. Banyak faktor yang melatar belakangi konsumen melakukan keputusan pembelian. Keputusan pembelian merupakan perilaku konsumen dalam memutuskan membeli atau tidak terhadap produk. Biasanya konsumen akan mempertimbangkan sebelum akan memutuskan pembelian sebuah produk yang akan dibelinya. Adapun penelitian ini menggunakan penelitian kuantitatif, populasi dalam penelitian ini berjumlah 1.091 mahasiswa. Sedangkan sampel yang digunakan 92 mahasiswa. Teknik analisis menggunakan uji anlisis regresi linier berganda. Hasil penelitian ini menunjukkan bahwa Product Knowledge berpengaruh terhadap keputusan pembelian, Brand Image berpengaruh terhadap keputusan pembelian, Brand Ambassador berpengaruh terhadap pengambilan keputusan. Dan secara bersamasama Product Knowledge, Brand Image, Brand Ambassador berpengaruh terhadap keputusan pembelian.

Kata kunci: Pengetahuan Produk, Citra Merek, Duta Merek, Keputusan Pembelian

\section{PENDAHULUAN}

Industri kopi instant dalam kemasan dalam perkembangannya di Indonesia mengalami trend kenaikan yang signifikan. Semakin ketatnya persaingan antara produsen kopi instant dalam kemasan dapat terlihat dari munculnya merek-merek kopi instan baru yang semakin berani dalam menyuguhkan berbagai macam varian rasa, prodak dan inovasi terbarunya kepada 
konsumen pecinta kopi. Banyaknya jenis kopi yang bermunculan yaitu kopi hitam, kopi robusta, arabika dan kopi susu sekarang ini muncul kopi putih atau yang lebih dikenal dengan white coffee. Perkembangan kopi putih yang semakin berkembang pesat saat ini sehingga banyak produsen kopi berlomba-lomba untuk memproduksi kopi putih. Perusahaan dapat mengambil peluang bisnis dari pesatnya perkembangan tersebut dan menciptakan inovasi yang lebih deferensiasi untuk dapat bersaing antar perusahaan (I Made Arya Dharmayana dan Gede Bayu Rahanatha, 2017: 19). Individu melakukan suatu keputusan pembelian di dasari oleh suatu keinginan serta kebutuhan untuk mengkonsumsi subuah produk. Keputusan pembelian ini berarti tindakan memilih dari dua pilihan alternatif atau lebih (Etta Mamang Sangadji dan Sopiah, 2013: 120). Tentunya akan cukup membingungkan bagi konsumen dalam memutuskan membeli salah satu produk kopi instant yang diinginkan dan dibutuhkannya. Oleh sebab itu product knowledge ini sendiri penting digunakan untuk mengetahui apakah seorang calon konsumen paham mengenai barang yang akan dibelinya. product knowledge merupakan kumpulan berbagai macam informasi mengenai produk, meliputi kategori produk, merek, terminolog produk, atribut, fitur produk, harga serta keprcayaan terhadap produk (Dony Herdianto, 2016: 88).

Setiap individu konsumen pastinya memiliki selera dan motivasi yang berbeda ketika membeli bahkan menikmati minuman kopi yang telah di beli. Salah satu hal yang membuat produk kopi tersebut dipilih diantaranya adalah karena citra merek (brand image) (Theo Hermawan Suzandoko dkk, 2019: 1742). Brand image yakni konsumen memiliki kepercayaan kepada merek dikarenakan merek tersebut sudah dikenali dan disukai sebelumnya. Oleh sebab itu, perusahaan harus mempunyai kekuatan dalam merek yang mereka ciptakan, kepercayaan prodak serta kemempuan komunikasi prodak yang mampu tertanam dalam benak konsumen (Yongky Hermawan, 2017: 1). Melalui image dari suatu brand yang mampu menumbuhkan pengetahuan dan cinta produk di benak konsumen, maka diharapkan memunculkan keinginan dalam pembelian produk yang direncanakan. Konsumen, sebelum memutuskan dalam membeli suatu produk, terlebih dahulu biasanya konsumen melakukan banyak pertimbangan, hal ini dikarenakan konsumen ingin mendapatkan produk yang sesuai dengan kebutuhan dan keinginannya sebagaimana perencanaannya dan kebutuhannya.

Wingsfood merupakan salah satu perusahaan yang mampu memasarkan prodak yang di buatnya dan dapat respon positif dari konsumen. Salah satu produk kopi Wingsfood yang pertama adalah adalah Top Coffee. Awal pertama kali produk Top Coffee dikeluarkan adalah pada tahun 2012 yang selanjutnya membuat beberapa varian. Diantaranya kopi sachet,yang salah satunya adalah Top White Coffee pada tahun 2013 (Rendy Tandarto dan Diah Dharmayanti, 2017: 1).

TOP White Coffee merupakan produk kopi yang di olah dari perpaduan biji kopi robusta dan arabika serta krimer yang istimewa, produk 
Pengaruh Product Knowledge, Brand Image, dan Brand Ambassador Terhadap Keputusan Pembelian Top White Coffe Mahasiswa FEBI IAIN Kudus 2016-2017

kopi ini juga mengklaim diri sebagai kopi nya orang Indonesia. Wingsfood telah menggaet 3 selebriti tanah air sebagai brand ambassador dari produk Top White Coffe diantara ialah Raline Shah, Ayushita Nugraha, dan Abimana Aryasatya. Brand Ambassador merupakan seseorang yang memiliki dan mempunyai passion terhadap brand dan serta mampu mempengaruhi konsumen untuk membeli atau menggunakan suatu produk yang di tawarkannya. (M Anang Firmansyah, 2019: 137). Meskipun begitu hal ini belum mampu mengangkat nama Top White Coffee dikalangan penikmat kopi.

\section{Gambar 1.1 Top Brand Index kopi instan White Coffe Tahun 2016-2019}

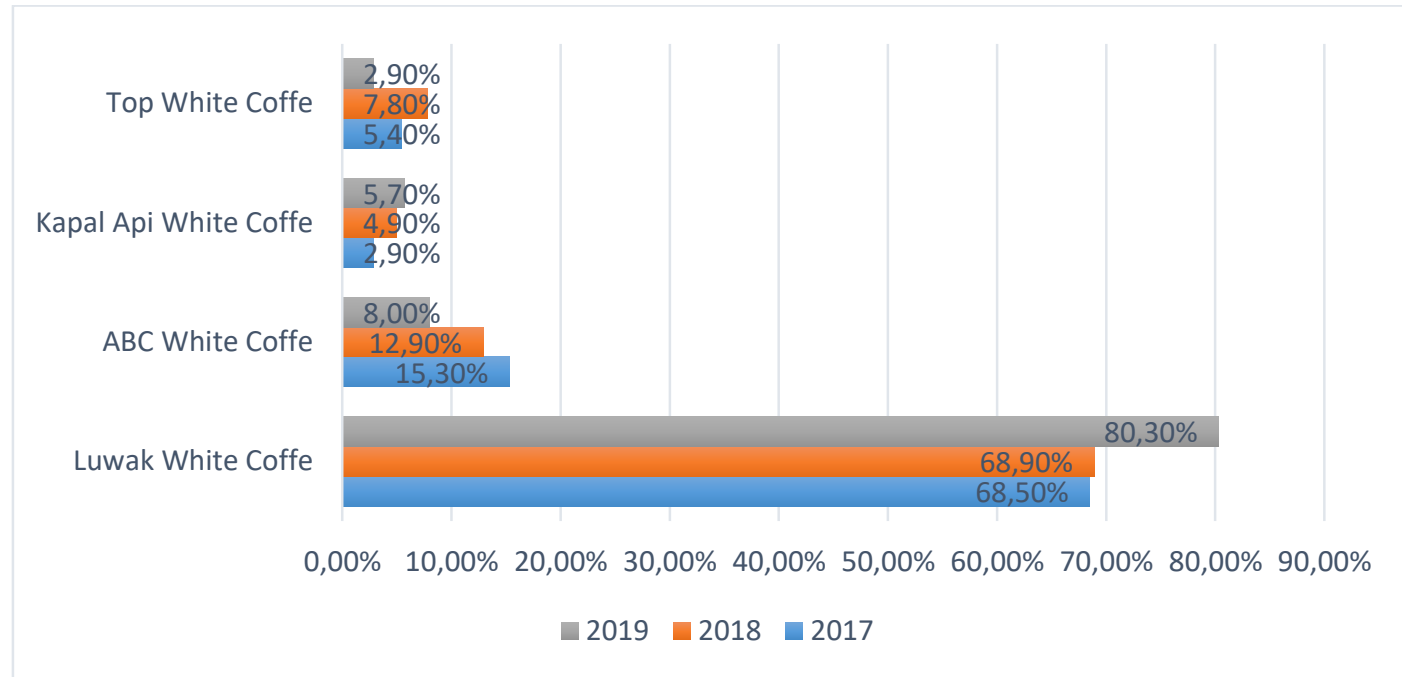

Sumber : Data Top Brand Indonesia, 2019

Tahun 2017 produk TOP White Coffee memiliki Top brand index akan tetapi masuk dalam urutan keempat yaitu sebesar 5,4\% untuk kategori White Coffee, baiknya, pada tahun 2018 mengalami peningkatan yang cukup signifikan terhadap Top brand index yaitu sebesar 7,8\% pada produk TOP White Coffee untuk kategori White Coffee. Kemudian pada tahun 2019 sangat di sayangkan produk TOP White Coffee mengalami penurunan yaitu sebesar $2,9 \%$.

Sebagaimana data diatas dapat dilihat bahwasannya terdapat penurunan penjualan yang terjadi pada tahun 2018 ke tahun 2019 yang awalnya $7.8 \%$ menurun menjadi $2.9 \%$ maka dari itu peneliti tertarik untuk meneliti permasalahan apa yang terjadi pada menurunnya penjualan dari produk kopi instan TOP White Coffee serta mengapa produk TOP White Coffe ini sendiri belum mampu bersaing dengan produk white coffe yang lainnya. Padahal secara pemasaran manajemen berupaya semaksimal mungkin dalam berupaya memaksimalkan penjualan. Berdasarkan uraian diatas, maka peneliti tertarik melakukan penelitian "Pengaruh Product Knowledge, Brand Image, Dan Brand Ambassador Terhadap Keputusan 
Pembelian Produk Top White Coffe (Studi Kasus Mahasiswa FEBI IAIN Kudus Tahun 2016-2017)".

\section{KAJIAN LITERATUR}

\section{Pengetahuan Produk (Product Knowledge)}

Sebagaimana teori yang dijelaskan Ujang Suwarman bahwa jika pengetahuan produk yang dimiliki oleh konsumen semakin luas maka akan semakin memberikan kepastian serta jaminan yang akan mereka dapatkan dari keputusan pembelian produk tersebut (Ujang Sumarwan, 2011: 186).

Zeithaml dalam Lin \& Lin yang dikutip dalam Adittya Warddhana dan Zainuddin Iba menyatakan bahwa suatu pengetahuan produk merupakan petunjuk intrinsik yang mana petunjuk instrinsik ini sangat penting untuk konsumen guna sebagai alat pertimbangan dalam melakukan evaluasi suatu produk sebelum melakukan pembelian. Konsumen akan condong mendahulukan petunjuk intrinsik guna melakukan penilaian terhadap suatu produk tertentu, semisalnya fungsi apa yang dimiliki oleh produk tersebut ataupun juga kualitas yang dimiliki produk tersebut baik atu kurang baik, akan tetapi bilamana petunjuk intrinsik terdapat ketidakbenaran, maka seprang konsumen akan beralih memakai petunjuk ekstrinsik seperti citra pada merek (Aditya Warddhana dan Zainuddin Iba, 2014: 4).

Pengetahuan produk ialah sekumpulan berbagai informasi mengenai karakteristik produk. Konsumen tentunya memiliki jenis dan tingkat pengetahuan yang berbeda-beda. Oleh karena itu disini konsumen dapat di kelompokkan ke dalam 3 (tiga) jenis pengetahuan produk diantaranya yaitu pengetahuan mengenai ciri atau karakter produk, konsekuensi atau manfaat positif menggunakan produk, dan nilai yang akan dipuaskan atau di capai oleh produk (M Anang Firmansyah, 2018: 66).

Apabila produsen faham dengan pengetahuan produk yang bernialai baik serta benar maka produsen akan dengan mudah melakukan konfirmasi pada seorang pembeli atau konsumen guna memastikan pembelian produk. Pengetahuan produk juga mencakup segala jenis informasi yang diproses oleh konsumen untuk memperoleh sebuah produk (Dony Herdianto, 2016: 88).

\section{Citra Merek (Brand Image)}

Kotler dan Amstrong mengemukakan bahwa "Marketers are interested in the beliefs that people formulate about specific products and services because these beliefs make up product and brand image that affect buying behavior". Hal ini dapat diartikan sebagai pemasar tertarik terhadap keyakinan seorang dalam menganalisa tentang produk atau jasa tertentu, karena keyakinan konsumen tersebut yang membentuk suatu produk dan citra merek yang akan mempengaruhi perilaku pembelian konsumen.

Brand atau merek ialah suatu penawaran dari sumber yang di ketahui (Philip Kotler dan Kevin Lane Keller, 2008: 14). Merek merupakan pembahasan tentang nama praduk, lambing praduk, tanda, desain, atau kombinasi dari semua ciri yang melekat dalam praduk untuk 
Pengaruh Product Knowledge, Brand Image, dan Brand Ambassador Terhadap Keputusan Pembelian Top White Coffe Mahasiswa FEBI IAIN Kudus 2016-2017

mengidentifikasikan produk atau jasa yang ditawarkan oleh sebuah perusahaan dan untuk mendeferensiasikan dari merek milik perusahaan lain. Merek adalah merupakan komitmen perusahaan yang mencirikan produk untuk secara konsisten memberika manfaat bagi konsumen. Merek yang baik tentunya akan memberikan garansi kualitas (Mas'ud Machfoedz, 2015: 176). Citra Merek sendiri tergambarkan dalambenak memori konsumen terhadap interpretasi sebuah merek, yang meliputi beberapa hal yakni diantaranya atribut, kelebihan, penggunaan, situasi para pengguna, dan karakteristik pemasar atau karakter produsen merek tersebut (M Anang Firmansyah, 2018: 87).

Kotler dalam Wua Gloria Sterie mendefinisikan brand Image adalah dengan nama, istilah, tanda, simbol rancangan, atau kombinasi dari semuanya yang itu semua dimaksudkan dalam mengidentifikasi barang atau jasa penjual atau kelompok penjual dan untuk mendiferensiasikannya dari barang atau jasa pesaing. Keller dalam Wua Gloria Sterie mengemukakan pengukuran brand image dapat menggunakan beberapa indikator akan sebuah merek, yaitu: Pertama, ialah kekuatan (strengthness) kekuatan adalah kelebihan-kelebihan yang terdapat dalam diri akan prodak yang semuanya itu bisa berasal dari sumberdaya yang berwujud maupun non berwujud serta capability akan produk. Kekuatan memberikan arti sesuatu yang belum ada atau belum dimiliki oleh para pesaing. Adapun yang masuk dalam kelompok kekuatan (strength) meliputi penampilan fisik produk, keberfungsian semua fasilitas produk, harga produk, maupun penampilan fasilitas pendukung dari produk tersebut. Kedua, ialah keunikan (uniqueness) keunikan adalah performa produk yang mampu mendeferensiasikan sebuah merek diantara merek lain dengan kata lain para pesaing. Keunikan akan muncul dari atribut produk yang menjadi kesan unik atau diferensiasi antara produk satu dengan produk lainnya yang memberikan latar belakang bagi konsumen bahwa konsumen harus membeli produk tersebut. Dan yang terakhir, ialah kesukaan (favorable) kesukaan berkaitan dalam memilih mana yang disukai dan unik yang berhubungan dengan merek, pemasar seharusnya menganalisis dengan penuh ketelitian terhadap konsumen dan kompetisi yang lain untuk memutuskan posisi terbaik bagi merek yang di ciptakannya. Kesukaan (favorable) lebih berhubungan dengan kemampuan merek tersebut agar mudah diingat oleh konsumen. Yang termasuk dalam kategori favorable ini antara lain kemudahan merek produk untuk diucapkan, kemampuan merek untuk tetap diingat oleh konsumen, kemudahan penggunaan produk, kecocokan konsumen dengan produk, serta kesesuaian antara kesan merek di benak pelanggan dengan citra yang diinginkan perusahaan atas merek yang bersangkutan (Wua Gloria Sterie Dkk, 2019: 3140-3141).

\section{Brand Ambassador}

Menurut teori Hovland Janis dan Kelley yaitu teori sumber kredibilitas (credibility source) menyatakan "That people are more likely to be persuades 
when source present it's self as credible". Hal ini dapat diartikan sebagai dimana semakin tinggi kredibilitas seorang komunikator maka akan semakin besar juga kemungkinan ia mempengaruhi khalayak. Peranan kredibilitas dalam proses penerimaan pesan dengan mengemukakan bahwa para bahwa para ahli akan lebih persuasif dibandingkan dengan yang bukan ahli. Orang biasannya lebih percaya dan cenderung lebih menerima dengan baik pesan yang disampaikan oleh seseorang yang memang ahli dibidang tersebut.

Untuk meningkatkan minat konsumen terhadap suatu produk maupun jasa biasanya perusahaan menggunakan brand ambassador. Brand ambassador adalah seorang yang dapat mewakili produk atau perusahaan dan dapat berbicara banyak tentang produk yang diwakilkan sehingga memberikan dampak yang besar pada penjualan produk (Ligia Stephani Samosir dkk, 2016: 234).

Brand ambassador adalah ikon budaya atau identitas,dimana mereka bertindak sebagai alat pemasaran yang mewakili pencapaian individualisme kejayaan manusia serta komodifikasi dan komersialisasi suatu produk. Turner, Bonner \& Marshall dikutip dalam Rennyta Yusiana dan Rifaatul Maulida menyebutkan "Increasingly", "celebrities are being asked to take on a certain amount of cultural activism as among the obligations which come with their visibility" (Muhammad Ikhsan Putra, dkk, 2014: 4).

Shimp dikutip dalam Rennyta Yusiana dan Rifaatul Maulida mengatakan bahwa brand ambassador merupakan orang yang mendukung suatu merek dari berbagai tokoh masyarakat populer, selain dari masyarakat populer dapat juga didukung oleh orang biasa dan lebih sering disebut sebagai endorser biasa. Karakteristik brand ambassador yaitu visibility (kepopuleran), credibility (keahlian), attraction (daya tarik) dan power (kekuatan) (Rennyta Yusiana dan Rifaatul Maulida, 2015: 312).

\section{Keputusan Pembelian}

Proses pengambilan keputusan pembelian sangat dipengaruhi oleh perilaku konsumen, proses tersebut sebenarnya merupakan proses pemecahan masalah dalam rangka memenuhi keinginan atau kebutuhan konsumen.

Menurut Peter dan Olson dalam Etta Mamang Sangadji dan Sopiah mengatakan bahwa, pengambilan keputusan konsumen adalah proses pemecahan masalah yang diarahkan pada sasaran. Inti dari pengambilan keputusan konsumen adalah prosess pengontegrasian yang mengombinasikan pengetahuan untuk mengevaluasi dua perilaku alternatif atau lebih dan memilih satu diantaranya. Pengambilan keputusan konsumen meliputi semua proses yang dilalui konsumen untuk mengenali masalah, mencari solusi, mengevaluasi alternatif, dan memilih diantara pilihan-pilihan (Etta Mamang Sangadji dan Sopiah, 2013: 332).

Menurut Mowen dan Minor dalam Sugiyarta Stanislaus dan Pundani Eki Pratiwi bahwa pengambilan keputusan konsumen meliputi semua proses yang dilalui konsumen dalam mengenali masalah, mencari solusi, mengevaluasi altematif, dan memilih di antara pilihan-pilihan pembelian mereka (Sugiyarta Stanislaus dan Pundani Eki Pratiwi, 2012: 2). 
Pengaruh Product Knowledge, Brand Image, dan Brand Ambassador Terhadap Keputusan Pembelian Top White Coffe Mahasiswa FEBI IAIN Kudus 2016-2017

Kotler dan Amstrong dalam Rian Darmawan dan Erni Martini menyatakan bahwa keputusan pembelian (purchase decision) konsumen adalah membeli merek yang paling disukai, tetapi dua faktor bisa berada antara niat pembelian dan keputusan pembelian (Rian Dermawan dan Erni Martini, 2019: 2).

Menurut Kotler \& Keller dalam Sanny Hanjaya menyatakan bahwa keputusan pembelian merupakan sebuah proses dimana konsumen mengetahui masalah yang dihadapi, selanjutnya mencari informasi produk atau merek dan mengevaluasi masing-masing pilihan yang dapat menyelesaikan masalah tersebut sehingga mengarah pada keputusan pembelian. Tahap-tahap yang dilalui oleh konsumen yaitu Problem Recognition, Information Search, Evaluation of Alternative, Purchase Decision, Postpurchase Behavior. Pengalaman konsumen terhadap produk tersebut akan menentukan apakah konsumen tersebut akan melakukan pembelian kembali atau tidak (Sanny Hanjaya, 2016: 183).

Terdapat beberapa hal dalam proses keputusan pembelian konsumen diantaranya ialah Pengenalan masalah atau kebutuhan, Pengenalan kebutuhan didefinisikan sebagai persepsi atas perbedaan antara keadaan yang diinginkan (situasi yang konsumen inginkan) dengan situasi aktual (yaitu situasi konsumen saat ini) yang memadai untuk menggugah dan mengaktifkan proses keputusan pembelian. Lalu, Pencarian informasi bila kebutuhan telah teridentifikasi konsumen kemudian akan mencari informasi mengenai berbagai macam alternatif untuk memenuhi kebutuhan tersebut. Kemudian, Evaluasi alternatif dalam tahap evaluasi alternatif ini, konsumen memproses informasi untuk mengevaluasi beberapa alternatif merek. Yang keempat, Tindakan pembelian Kotler \& Keller dalam Aditya Wardhana dan Zainuddin Iba, menyatakan bahwa setelah membandingkan beberapa alternatif, selanjutnya konsumen akan memutuskan apakah akan melakukan pembelian atau tidak atas produk atau jasa yang ditawarkan suatu perusahaan. Pada umumnya konsumen akan memutuskan untuk membeli produk atau jasa sesuai dengan kebutuhan dan keinginan nya.

Ketika melaksanakan pembelian, konsumen dapat membuat 5 sub keputusan pembelian: pemilihan merek, pemilihan saluran pembelian, jumlah pembelian, penentuan waktu pembelian dan metode pembayaran. Dan yang terakhir ialah, Perilaku setelah pembelian ketika memutuskan untuk membeli suatu produk atau jasa, pembeli mempunyai harapan dari produk atau jasa yang dibelinya tersebut. Menurut Schiffman \& Kanuk dalam Aditya Wardhana dan Zainuddin Iba, perilaku setelah pembelian ini dapat diukur dengan kepuasan dan ketidakpuasan pembeli. Kotler \& Amstrong Aditya Wardhana dan Zainuddin Iba, menyatkan bahwa jika pengalaman yang diperoleh pembeli menyenangkan atau membuat ia puas, maka konsumen cenderung akan membeli ulang, menceritakan kepuasannya kepada orang lain, tidak terlalu memperhatikan atau tertarik pada produk 
pesaing dan konsumen yang puas akan membeli produk lainya dari perusahaan yang sama (Aditya Wardhana dan Zainuddin, 2014: 5-6).

\section{Kerangka Berfikir dan Hipotesis}

\section{Gambar 1.2 Kerangka Berfikir}

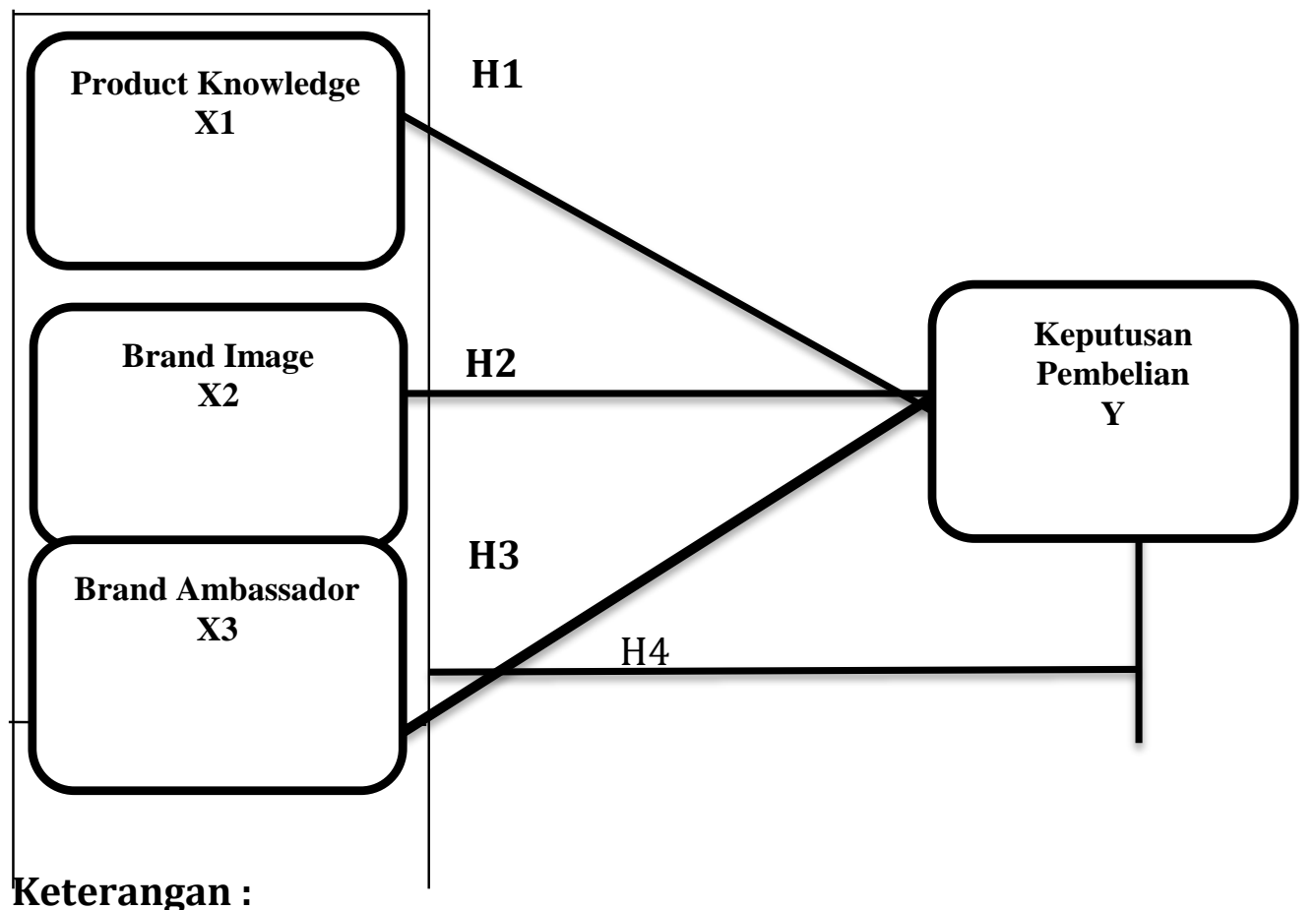

1) H1 : Garis yang menghubungkan antara variabel product knowledge (X1) ke keputusan pembelian (Y) adalah garis parsial.

2) H2 : Garis yang menghubungkan antara variabel brand image (X2) ke keputusan pembelian (Y) adalah garis parsial.

3) H3 : Garis yang menghubungkan antara variabel brand ambassador (X3) ke keputusan pembelian (Y) adalah garis parsial.

4) H4 : Garis yang menghubungkan antara product knowledge (X1), brand image (X2) dan brand ambassador (X3) ke keputusan pembelian $(\mathrm{Y})$ secara bersamaan adalah garis simultan.

Terkait judul penlitian, maka dalam penelitian ini penulis mengajukan hipotesis sebagai berikut:

1. Pengaruh Product Knowledge Terhadap Keputusan Pembelian Pengetahuan produk ialah gabungan berbagai informasi mengenai suatu produk. Konsumen mempunyai tingkat pengetahuan yang berbeda, konsumen dapat mempunyai tiga jenis pengetahuan produk yaitu pengetahuan tentang ciri atau karakter produk, konsekuensi atau manfaat positif menggunakan produk, dan nilai yang akan dipuaskan atau di capai oleh produk (M Anang Firmansyah, 2019: 66).

Hasil penelitian sebelumnya yang dilaakukan oleh Indarto Candra Yoesmanam yang meneliti tentang "Pengaruh Pengetahuan Produk 
Pengaruh Product Knowledge, Brand Image, dan Brand Ambassador Terhadap Keputusan Pembelian Top White Coffe Mahasiswa FEBI IAIN Kudus 2016-2017

dan Persepsi Kualitas Produk Terhadap Keputusan Pembelian Pada Kosmetik Organik" hasil penelitian ini menunjukkan bahwa adanya hubungan yang positif antara pengetahuan produk dengan keputusan pembelian. Hasil tersebut menunjukan bahwa semakin konsumen memiliki banyak pengetahuan produk akan kosmetik organik Melilea Botanical Skin Care jadi semakin cepat pula seorang konsumen melakukan keputusan pembelian. diketahui bahwasannya pengetahuan produk berpengaruh simultan terhadap keputusan pembelian pada kosmetik organik. Dari data penelitian terdahulu maka penulis berpendapat bahwa pengetahuan produk ini berpengaruh terhadap keputusan pembelian. Berdasafrkan uraian di atas maka dapat di rumuskan hepotesis sebagai berikut:

$\mathrm{H}_{1}$ : Diduga terdapat pengaruh product knowledge terhadap keputusan pembelian.

\section{Pengaruh Brand Image Terhadap KeputusanPembelian}

Brand image berarti konsumen memberikan kepercayaan pada sebuah merek karena seorang konsumen merasa menyukai merk tersebut ataupun karena merek tersebut populer pada kalangan masyarakat. Seorang produsen harus memiliki kekuatan pada merk yang mereka buat atau produksi agar konsumen berasumsi positif terhadap merek yang mereka ciptakan (Yongki Hermawan, 2017: 1).

Hasil penelitian sebelumnya yang dilakukan oleh Ni Made Rahayu Wulandari dan I Ketut Nurcahya "Pengaruh Celebrity Endorser, Brand Image, dan Brand trust Terhadap Keputusan Pembelian Clear Shampoo Di Kota Denpasar" hasil penelitian tersebut menunjukan bahwa brand image berpengaruh terhadap minat beli. Nilai signifikan brand image $(\mathrm{X} 2)>0,05$ maka $\mathrm{H}_{0}$ diterima dan nilai $t_{\text {hitung }}=5,239>$ dari ttabel=1,658 maka $\mathrm{H}_{0}$ ditolak, positif, erat, dan signifikan dalam arti kedua variabel antara brand image dengan keputusan pembelian Clear shampoo di Kota Denpasar saling berpengaruh besar/erat satu sama lain dengan didasarkan pada perhitungan olah data statistik yang signifikan. Hal ini menunjukkan bahwa brand image pada Clear shampoo sangat melekat di benak masyarakat Kota Denpasar sehingga mampu sebagai pendorong masyarakat untuk melakukan pembelian diketahui bahwasannya brand image berpengaruh simultan terhadap keputusan pembelian pada produk clear shampoo di kota denpasar. Dari data penelitian terdahulu maka penulis berpendapat bahwa brand image ini berpengaruhterhadap keputusan pembelian. Berdasarkan pemaparan tersebut maka dapat dirumuskan hepotesis sebagai berikut:

$\mathrm{H}_{2}$ : Diduga terdapat pengaruh brand imageterhadap keputusan pembelian. 


\section{Pengaruh Brand Ambassador Terhadap Keputusan Pembeelian}

Shimp dalam Rennyta Yusiana dan Rifaatul Maulida menyatakan bahwa brand ambassador ialah suatu individu maupun kelompok yang mendukung suatu merk dan berasal dari berbagai tokoh masyarakat yang populer, selain dari masyarakat populer dapat juga didukung oleh orang biasa namun lebih seringnya disebut dengan endorser biasa. Karakteristik seorang brand ambassador yaitu visibility (kepopuleran), credibility (keahlian), attraction (daya tarik) dan power (kekuatan) (Rennyta yusiana dan rifatul maulida, 2015: 312).

Hasil penelitian sebelumnya yang dilakukan oleh Wua Gloria Sterie, James D. D Massie, dan Djurwati Seopono "Pengaruh brand ambassador dan brand image terhadap keputusan pembelian produk PT. Telesindo shop sebagai distributor utama telkomsel di manado" Hasil pengujian pada penelitian itu menyatakab bahwasanya brand ambassador berpengaruh signifikan terhadap keputusan pembelian dan memiliki nilai yang positif. Hasil tersebut dapat dilihat terlihat nilai signifikan sebesar 0,174 yang mana berrti < tingkat signifikan $0,05(1,74 \%<0,05 \%)$ atau nilai thitung $>$ tabel ( $1,368>1,982$ ) dan memiliki nilai B positif yaiitu sebeesar 0,286 . Hal ini menjelaskan bahqa hasil penelitian ini menunjukan kondisi yang signifikan yang berarrti semakiin tinggi brand ambassador makaa tingkat keputusan pembelian semakin tinggi atau naik sebesar 0,286 atau sebesar 28,6\%. Diketahui bahwasannya brand ambassador berpengaruh simultan terhadap keputusan pembelian pada produk PT.Telesindo shop sebagaii disttributor utama telkomsel di kota manado. Dari data penelitian terdahulu makaa peneliti berpendapat bahwasanya brand ambassador ini berpengaruh terhadap keputusan pembelian. Berdasrarkan uraian tersrebut maka dapat dirumsuskan hepotesis sebagai berikut:

$\mathrm{H}_{3}$ : Diduga terdapat pengaruh brand ambassadorterhadap keputusan pembelian.

4. Pengaruh Product Knowledge, Brand Image, dan Brand Ambassador Terhadap Keputusan Pembelian

Penelitian-penelitian terdahulu diatas maka peneliti berpendapat bahwa product knowledge, brand image dan brand ambassador merupakan faktor pendorong keputusan pembelian konsumen dalam membeli suatu produk. product knowledge, brand image dan brand ambassador secara besrsama-sama berpengaruh terhadap keputusan pembelian. Namun, di antara beberapa faktor tersebut terdapat satu faktor yang paling dominan mempengaruhi kinerja karyawan dalam suatu perusahan. Berdasasrkan pemaparan diatas maka dapat di rumuskan hepotesis sebagai berikut: 
Pengaruh Product Knowledge, Brand Image, dan Brand Ambassador Terhadap Keputusan Pembelian Top White Coffe Mahasiswa FEBI IAIN Kudus 2016-2017

$\mathrm{H}_{4}$ : Diduga terdapat pengaruh yang simultan antara product knowledge, brand image dan brand ambassador terhadap keputusan pembelian.

\section{METODE PENELITIAN}

Adapun Jenis penelitian yang digunakan pada penelitian ini ialah penelitian asosiatif, yaitu penelitian yang bertujuan untuk mengetahui hubungan antara dua variabel atau lebih (V Wiratna sujarweni, 2015: 16). Pendekatan yang digunakan dalam penelitian ini sendiri ialah pendekatan kuantitatif. Penelitian kuantitatif pada dasarnya ialah suatu metode penelitian yang menekankan penganalisisannya terhadap data-data numerical (angka) yang kemudian diolah dengan metode statistik (Saifudin Azwar, 1997: 5). Serta uji analisis yang di gunakan adalah uji regresi linier berganda.

Populasi yang digunakan pada penelitian ini ialah seluruh mahasiswa dan mahasiswi fakultas Ekonomi dan Bisnis Islam IAIN Kudus tahun 2016-2017 yaitu sebanyak 1091 mahasiswa. Untuk menentukan berapa minimal sampel yang dibutuhkan jika ukuran populasinya telah diketahui, maka dapat menggunakan rumus Slovin. Berdasarkan dari jumlah populasi 1091 mahasiswa, dengan menggunakan rumus Slovin maka didapatkan jumlah sampel sebanyak 91,60 dan dibulatkan menjadi 92 responden.

Metode pengumpulan data yang digunakan dalam penelitian ini ialah dengan menggunakan kuisioner yang berisi butir pertanyaan dan dibagikan kepada 92 responden yang sudah pernah membeli dan mengkonsumsi produk Top white coffe. Pada kuisioner, pengukuran variabel menggunakan skala Likert. Teknik analisis dataa yang akan di gunakan pada penelitian ini adalah menggunakan analisis SPSS Ver.21. SPSS (Statistical Package for the Social Sciences) yaitu software yang fungsinya untuk menganalisis data, melakukan perhitungan statistik baik untuk statistik parametrik maupun nonparametrik dengan basis windows (Imam Ghozali, 2018: 15).

\section{PEMBAHASAN}

\section{Hasil Uji Validitas dan Reliabilitas Instrumen}

\section{a. Uji Validitas}

Tabel 1.1

\section{Hasil Uji Validitas Instrumen}

\begin{tabular}{ccccc} 
Variabel & Item & rhitung & rtabel & Keterangan \\
& & & & \\
Product & $\mathrm{X} 1.1$ & 0.664 & 0.1726 & Valid \\
Knowledge & $\mathrm{X} 1.3$ & 0.817 & 0.1726 & Valid \\
& $\mathrm{X} 1.4$ & 0.684 & 0.1726 & Valid \\
& $\mathrm{X} 1.5$ & 0.735 & 0.1726 & Valid \\
Brand Image & $\mathrm{X} 2.1$ & 0.734 & 0.1726 & Valid \\
& $\mathrm{X} 2.2$ & 0.806 & 0.1726 & Valid \\
& $\mathrm{X} 2.3$ & 0.766 & 0.1726 & Valid \\
\hline
\end{tabular}




\begin{tabular}{ccccc} 
& X2.4 & 0.606 & 0.1726 & Valid \\
& X2.5 & 0.718 & 0.1726 & Valid \\
& X2.6 & 0.841 & 0.1726 & Valid \\
& X2.7 & 0.363 & 0.1726 & Valid \\
& X3.1 & 0.852 & 0.1726 & Valid \\
Brand & X3.2 & 0.786 & 0.1726 & Valid \\
Ambassador & X3.3 & 0.880 & 0.1726 & Valid \\
& X3.4 & 0.858 & 0.1726 & Valid \\
& X3.5 & 0.760 & 0.1726 & Valid \\
& X3.6 & 0.543 & 0.1726 & Valid \\
& Y1.1 & 0.640 & 0.1726 & Valid \\
Keputusan & Y1.2 & 0.652 & 0.1726 & Valid \\
Pembelian & Y1.4 & 0.786 & 0.1726 & Valid \\
& Y1.5 & 0.473 & 0.1726 & Valid \\
& Y1.6 & 0.724 & 0.1726 & Valid \\
& Y1.7 & 0.747 & 0.1726 & Valid \\
& Y1.8 & 0.844 & 0.1726 & Valid \\
\hline
\end{tabular}

Sumber: Data Primer yang diolah, 2020.

Dari tabel diatas dapat disimpulkan bahwa semua butir pertanyaan dikatakan valid karena $r_{\text {hitung }}$ lebih besar dari $r_{\text {tabel }}(0.1726)$ dan bernilai positif.

b. Uji Reabilitas

Tabel 1.2

Hasil Uji Reliabilitas Instrumen

$\begin{array}{cccc}\text { No } & \text { Variabel } & \text { Cronbach's Alpha } & \text { Keterangan } \\ 1 & \text { Product Knowledge } & \mathbf{0 , 6 7 6} & \text { Reliabel } \\ 2 & \text { Brand Image } & \mathbf{0 , 8 1 3} & \text { Reliabel } \\ 3 & \text { Brand Ambassador } & \mathbf{0 , 8 7 5} & \text { Reliabel } \\ 4 & \text { Keputusan Pembelian } & \mathbf{0 , 8 0 6} & \text { Reliabel }\end{array}$

Sumber: Data primer yang diolah, 2020.

Dari tabel diatas dapat di ketahui bahwa masing-masing dari Variabel memiliki Cronbach Alpha> 0,60 $(\alpha>0,60)$, yang artinya bahwa semua variabel X1, X2, X3 dan Y dapat dikatakan Reliabel.

2. Uji Asumsi Klasik

a. Uji Multikolinieritas

\section{Tabel 1.3}

\begin{tabular}{cccc} 
Variabel & Tolerance & VIF & Keterangan \\
& & & \\
Product Knowledge & $\mathbf{0 , 3 3 6}$ & $\mathbf{2 . 9 7 7}$ & Tidak \\
Brand Image & $\mathbf{0 , 6 5 5}$ & $\mathbf{1 . 5 2 8}$ & Multikolonieritas \\
& & Tidak \\
Brand Ambassador & $\mathbf{0 , 3 0 5}$ & $\mathbf{3 . 2 7 4}$ & Tidak \\
\hline
\end{tabular}


Pengaruh Product Knowledge, Brand Image, dan Brand Ambassador Terhadap Keputusan Pembelian Top White Coffe Mahasiswa FEBI IAIN Kudus 2016-2017

Multikolonieritas

\section{Hasil Uji Multikolonieritas}

Sumber : Data primer yang diolah, 2020.

Berdasarkan data yang telah diolah dalam tabel coefficients, dapat dilihat bahwa nilai tolerance untukproduct knowledge sebesar 0,336, brand image0,655, dan brand ambassador 0,305 lebih dari $(\geq)$ 0.10. Karena korelasinya di bawah 90\%, maka dikatakan tidak terjadinya multikolonieritas. Sedangkan semua variabel bebas memiliki nilai VIF kurang dari ( $\leq$ ) 10 yaitu product knowledge sebesar 2.977, brand image 1.528, danbrand ambassador sebesar 3.274. Sehingga dapat disimpulkan bahwa tidak terjadi penyimpangan asumsi klasik multikolinearitas antara variabel independen dalam model regresi.

b. Uji Autokorelasi

Tabel 1.4

Hasil Uji Autokorelasi

$\begin{array}{llllll}\text { Model } & \text { R } & \begin{array}{c}\text { R } \\ \text { Square }\end{array} & \begin{array}{l}\text { Adjusted } \\ \text { R Square }\end{array} & \begin{array}{l}\text { Std. Error } \\ \text { of } \begin{array}{c}\text { Durbin- } \\ \text { Estimate }\end{array}\end{array} & \begin{array}{l}\text { Watson } \\ \text { the }\end{array} \\ 1 & 0.946^{\mathrm{a}} & 0.895 & 0.891 & 0.19401 & \mathbf{1 . 9 3 1}\end{array}$

Sumber : Data primer yang diolah, 2020.

Dari hasil tabel diatas dapat dilihat nilai Durbin Watson hitung ialah sebesar 1.931, maka dinyatakan tidak terdapatnya autokorelasi positif dimana nilai (DW) $1.931>(\mathrm{dU}) 1.7523$ dan juga tidak terdapat autokorelasi negatif dimana nilai 4-DW= $2.069>(\mathrm{dU}) 1.7523$, sehingga dapat ditarik kesimpulan bahwa tidak adanya autokorelasi sama sekali baik autokorelasi positif maupun autokorelasi negatif.

\section{c. Uji Heterokedastisitas}

\section{Gambar 1.3 \\ Hasil Uji Heteroskedastisitas}

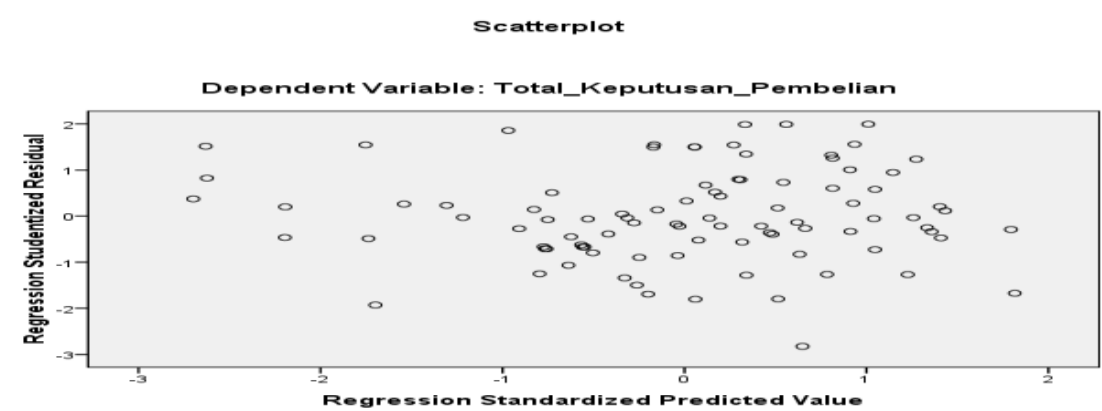

Dari grafik scatterplots diatas terlihat bahwa titik-titik menyebar secara acak serta tersebar baik di atas maupun di bawah angka 0 pada sumbu $Y$ (keputusan pembelian). Hal ini dapat 
disimpulkan bahwa tidak terjadi heteroskedastisitas pada model regresi ini, sehingga model regresi ini layak di pakai.

\section{d. Uji Normalitas}

\section{Gambar 1.4}

\section{Hasil Uji Normalitas}

Histogram

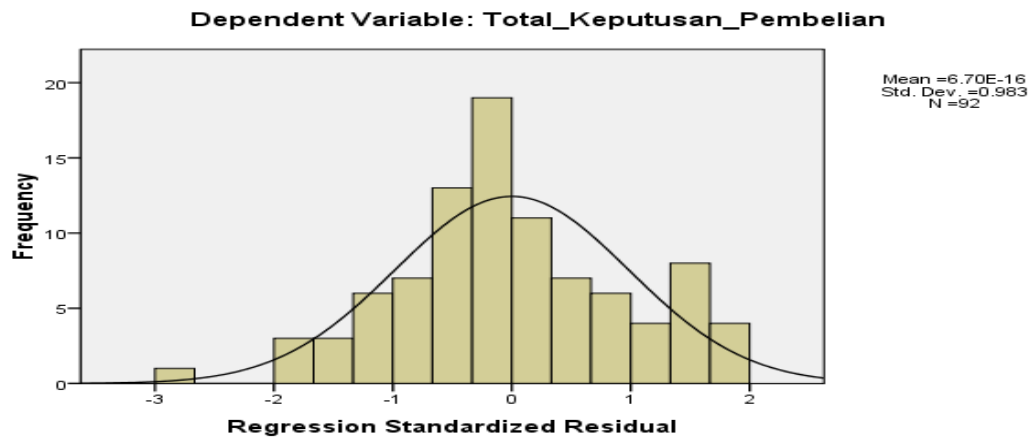

Dapat dilihat pada grafik histogram diatas menjelaskan bahwasanya residual data telah menunjukkan kurva normal yang membentuk lonceng sempurna.

Gambar 1.5

Hasil Uji Normalitas

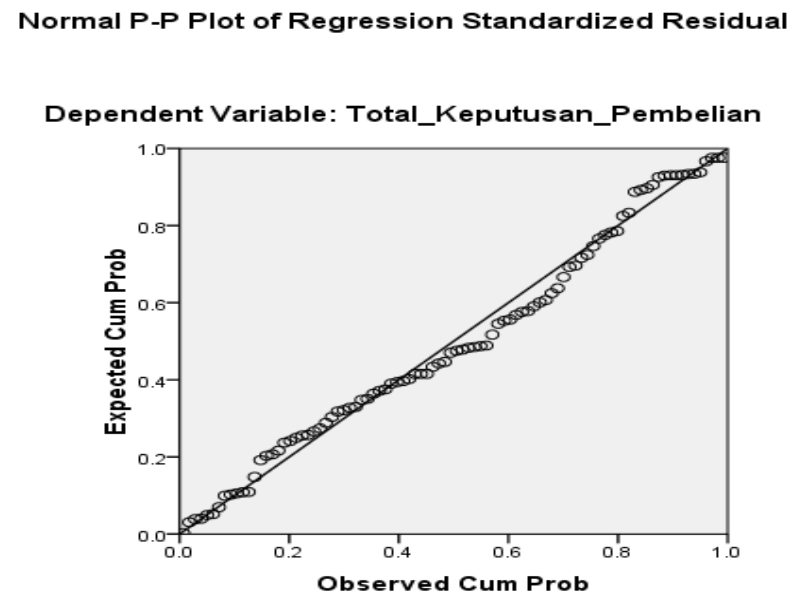

Sedangkan grafik normal P- Plot menjelaskan bahwasanya terdapat titik-titik yang menyebar pada sekitar garis diagonal serta penyebarannya mengikuti arah garis diagonal. Dengan demikian, data yang digunakan telah memenuhi asumsi klasik serta dapat di katakan data tersebut normal. 
Pengaruh Product Knowledge, Brand Image, dan Brand Ambassador Terhadap Keputusan Pembelian Top White Coffe Mahasiswa FEBI IAIN Kudus 2016-2017

\begin{tabular}{lcr}
\multicolumn{1}{c}{ Tabel 1.5 } & \\
& Hasil Uji Normalitas & \multicolumn{2}{c}{$\begin{array}{l}\text { Unstandardized } \\
\text { Residual }\end{array}$} \\
& & 92 \\
$\mathrm{~N}$ & Mean & .0000000 \\
Normal Parameters ${ }^{\mathrm{a}}$ & Std. Deviation & 1.52625833 \\
Most Extreme Differences & & .077 \\
Absolute & & .077 \\
& Positive & -.065 \\
Kolmogorov-Smirnov Z & Negative & .734 \\
Asymp. Sig. (2-tailed) & &. $\mathbf{6 5 3}$ \\
\hline Sumber : Data primer yang diolah, 2020
\end{tabular}

Berdasarkan hasil pengujian diatas menunjukkan bahwa variabel residual terdistribusi normal. Hal itu dapat di lihat bahwasanya signifikansi (Asymp. Sig.) ialah 0.653. Karena signifikansi $0.653>0,05$, maka hal ini menunjukkan bahwa model regresi memenuhi asumsi normalitas.

\section{Uji Hipotesis}

a. Analisis Linier Berganda

Tabel 1.6

Hasil Uji Linier Berganda

Keterangan Nilai Koefisien Sig.

$\begin{array}{ccc}\text { Konstanta } & 0.337 & 0.014 \\ \text { Product Knowledge } & \mathbf{0 . 1 4 6} & \mathbf{0 . 0 0 5} \\ \text { Brand Image } & \mathbf{0 . 2 9 4} & \mathbf{0 . 0 0 0} \\ \text { Brand Ambassador } & \mathbf{0 . 4 5 2} & \mathbf{0 . 0 0 0}\end{array}$

Sumber : Data primer yang diolah, 2020.

Dapat dilihat pada tabel diatas bahwa nilai koefisien regresi product knowledge, brand image, dan brand ambassador Koefesiennya bernilai positif artinya terjadi hubungan positif antara product knowledge, brand image, dan brand ambassador terhadap keputusan pembelian, maka apabila semakin baik product knowledge, brand image, dan brand ambassador maka keputusan pembelian semakin meningkat pula.

b. Uji T (parsial)

Tabel 1.7 


\section{Hasil Uji Persial (Uji t)}

\begin{tabular}{|c|c|c|c|c|}
\hline Variabel & $t_{\text {hitung }}$ & $t_{\text {tabel }}$ & Sig. & Keterangan \\
\hline Product Knowledge & 2.892 & 1.6622 & 0.005 & $\begin{array}{l}\text { Berpengaruh dan } \\
\text { Signifikan }\end{array}$ \\
\hline Brand Image & 7.067 & 1.6622 & 0.000 & $\begin{array}{l}\text { Berpengaruh dan } \\
\text { Signifikan }\end{array}$ \\
\hline Brand Ambassador & 9.401 & 1.6622 & 0.000 & $\begin{array}{l}\text { Berpengaruh dan } \\
\text { Signifikan }\end{array}$ \\
\hline
\end{tabular}

Sumber : Data primer yang diolah, 2020.

Berdasarkan hasil uji t diatas dapat di simpulkan bahawa :

a) Adanya pengaruh product knowledge terhadap keputusan pembelian Top white coffe pada Mahasiswa Fakultas Ekonomi dan Bisnis Islam IAIN Kudus tahun 2016-2017. Karena nilai thitung sebesar 2.892 lebih besar dari pada tabel 1.6622 dengan signifiksn sebesar 0,005 lebih kecil dari 0,05. Oleh karena itu, hipotesis pertama $\left(\mathrm{H}_{1}\right)$ yang menyatakan product knowledge $\left(\mathrm{X}_{1}\right)$ berpengaruh terhadap keputusan pembelian Top white coffe pada Mahasiswa Fakultas Ekonomi dan Bisnis Islam IAIN Kudus tahun 2016-2017. Sehingga H1 diterima. Penelitian ini sesuai dengan penelitian yang di lakukan oleh indarto candra yoesmanam tahun 2015 menunjukkan bahwa pengetahuan produk berpengaruh terhadap keputusan pembelian. Jika konsumen mengetahui tentang manfaat, atribut, karakteristik, kelebihan besar kemungkinan konsumen akan memutuskan untuk melakukan pembelian terhadap prodak kita

b) Adanya pengaruh brand image terhadap keputusan pembelian Top white coffe pada Mahasiswa Fakultas Ekonomi dan Bisnis Islam IAIN Kudus tahun 2016-2017. Karena nilai thitung sebesar 7.067 lebih besar dari pada tabel 1.6622 dengan signifikan sebesar 0,000 lebih kecil dari 0,05. Oleh karena itu, hipotesis kedua $\left(\mathrm{H}_{2}\right)$ yang menyatakan brand image $\left(\mathrm{X}_{2}\right)$ berpengaruh terhadap keputusan pembelian Top white coffe pada Mahasiswa Fakultas Ekonomi dan Bisnis Islam IAIN Kudus tahun 2016-2017. Sehingga H2 diterima. Penelitian ini sesuai dengan penelitian yang di lakukan oleh $\mathrm{Ni}$ Made Rahayu Wulandari dan I Katut Nur Cahya tahun 2015 menunjukkan bahwa brand image berpengaruh terhadap keputusan pembelian. Dengan kekuatan merk yang di bangun oleh para pengusaha dengan memiliki keunikan, ciri khusus, keandalan dll memungkinkan konsumen lebih memutuskan pembelian terhadap produk kita.

c) Adanya Pengaruh brand ambassador terhadap keputusan pembelian Top white coffe pada Mahasiswa Fakultas Ekonomi dan Bisnis Islam IAIN Kudus tahun 2016-2017 . Karena nilai thitung 
Pengaruh Product Knowledge, Brand Image, dan Brand Ambassador Terhadap Keputusan Pembelian Top White Coffe Mahasiswa FEBI IAIN Kudus 2016-2017

sebesar 9.401 lebih besar dari pada tabel 1.6622 dengan signifikan sebesar 0,000 lebih kecil dari 0,05. Oleh karena itu, hipotesis ketiga $\left(\mathrm{H}_{3}\right)$ yang menyatakan brand ambassador $\left(\mathrm{X}_{3}\right)$ berpengaruh terhadap keputusan pembelian Top white coffe pada Mahasiswa Fakultas Ekonomi dan Bisnis Islam IAIN Kudus tahun 2016-2017. H3 diterima. Penelitian ini sesuai dengan penelitian yang di lakukan oleh Wua Gloria dkk, tahun 2015 menunjukkan bahwa brand ambassador berpengaruh terhadap keputusan pembelian. Dengan peran brand ambassador menjadikan konsumen merasa tertarik untuk melakukan pembelian dikarenakan faktor Pablic figure yang melatarbelakanginya.

\section{c. Uji Silmutan (Uji F)}

\section{Tabel 1.8}

\section{Hasil Uji Silmutan (Uji F)}

\begin{tabular}{llllll} 
Model & $\begin{array}{l}\text { Sum of } \\
\text { Squares }\end{array}$ & Df & $\begin{array}{l}\text { Mean } \\
\text { Square }\end{array}$ & F & Sig. \\
Regression & 28.107 & 3 & 9.369 & $\mathbf{2 4 8 . 9 1 9}$ & $\mathbf{0 . 0 0 0}^{\mathbf{b}}$ \\
Residual & 3.312 & 88 & 0.038 & & \\
Total & 31.419 & 91 & & & \\
\hline Sumber : Data primer yang diolah, 2020 &
\end{tabular}

Sumber : Data primer yang diolah, 2020

Berdasarkan table yang tercantum diatas menunjukkan bahwa Fhitung sebesar 248.919 dengan tingkat signifikansi sebesar 0,000 dimana lebih kecil dari $\alpha$ yaitu sebesar 0,05 karena $F_{\text {hitung }}$ lebih besar dari $\mathrm{F}_{\text {tabel }}$ yaitu 2.14 Maka keputusannya adalah menerima hipotesis yang menyatakan bahwa terdapat pengaruh yang signifikan antara product knowledge, brand image, brand ambassador secara bersama-sama terhadap keputusan pembelian.

d. Koefesien Derteminan (R2)

Table 1.9

Hasil Analisis Koefesien Derteminan $\left(R^{2}\right)$

\begin{tabular}{lllll} 
Model & $\mathbf{R}$ & R Square & $\begin{array}{l}\text { Adjusted R } \\
\text { Square }\end{array}$ & $\begin{array}{l}\text { Std. Error of the } \\
\text { Estimate } \\
1\end{array}$ \\
$0.946^{\mathrm{a}}$ & 0.895 & $\mathbf{0 . 8 9 1}$ & 0.19401 \\
\hline
\end{tabular}

Sumber : Data primer yang diolah, 2020.

Dari table di atas dapat disimpulkan bahwa terdapat hubungan antara dua variabel yaitu variabel dependen dan independen. Karena nilai adjusted $R$ square sebesar 0.891 atau $89.1 \%$ yang mana nilai ini mendekati angka satu maka dapat di katakan sumbangan dari variabel independen terhadap variabel dependen semakin besar. Hal ini berarti model yang digunakan semakin kuat. Sedangkan sisanya $(100 \%-89.1 \%=10.9 \%)$ dipengaruhi oleh variabel yang lain yang mana tidak termasuk didalam penelitian ini.

\section{SIMPULAN}


Berdasarkan hasil perhitungan statistik yang telah dilakukan, maka dapat diperoleh kesimpulkan sebagai berikut: Variable product knowledge berpengaruh terhadap keputusan pembelian produk Top white coffe pada mahasiswa Fakultas Ekonomi dan Bisnis Islam IAIN Kudus tahun 2016-2017. Variable brand image berpengaruh terhadap keputusan pembelian produk Top white coffe pada mahasiswa Fakultas Ekonomi dan Bisnis Islam IAIN Kudus tahun 2016-2017. Variabel brand ambassador berpengaruh terhadap keputusan pembelian produk Top white coffe pada mahasiswa Fakultas Ekonomi dan Bisnis Islam IAIN Kudus tahun 2016-2017. Dan secara bersama-sama pada variabel product knowledge, brand image, dan brand ambassador berpengaruh terhadap keputusan pembelian produk Top white coffe. Penelitian yang sudah kami lakukan tentunya masih banyak kendala dan keterbatasan, oleh sebab itu jika ingin melanjutkan penelitian yang serupa bisa memperluas subjek penelitian, seperti mahasiswa IAIN Kudus secara umum, bahkan mahasiswa se-kabupaten Kudus agar mendapatkan hasil yang lebih luas dan tentunya sangat bermanfaat bagi khalayak umum. 
Pengaruh Product Knowledge, Brand Image, dan Brand Ambassador Terhadap Keputusan Pembelian Top White Coffe Mahasiswa FEBI IAIN Kudus 2016-2017

\section{DAFTAR PUSTAKA}

Algifari. (2000). Analisis Regresi Teori, Kasus, dan Solusi: Edisi 2. Yogyakarta: BPFE.

Azwar, S. (1997). Metode Penelitian. Yogyakarta: Pustaka Belajar.

Dharmayana, I. Rahanatha. Gede, B. (2017). Pengaruh Brand Equity Brand Trust Brand Preference dan Kepuasan Konsumen Terhadap Niat Membeli Kembali. E-Jurnal Manajemen Universitas Udayana. Vol.6 No.4.

Firmansyah, M. Anang. (2019). Pemasaran Produk dan Merek (Planning and Strategy). Pasuruan: Qiara Media.

Firmansyah. M. (2018). Perilaku Konsumen Sikap dan Pemasaran. Yogyakarta: CV Budi Utama.

Gozali, I. (2011). Aplikasi Analisis Multivariate Dengan Program IBM SPSS 19. Semarang: Undip.

Ghozali, I. (2018). Aplikasi Analisis Multivariate Dengan Program IBM SPSS 25. Semarang: Undip.

Herdianto, D. (2016). Creative Selling Everyday. Jakarta: PT Elex Media Komputindo.

Hasan, M. (2001). Pokok-pokok Materi Statistik 1 (Statistik Deskriptif). Jakarta: PT Bumi Aksara.

Hermawan, Y. (2017). Analisis Pengaruh Celebrity Endorsement Lee Minho Dalam Iklan Luwak White Koffie Terhadap Brand Image dan Brand Repurchase Intention. Jurnal Manajemen Pemasaran, Vol.4 No.1.

Kotler, P. Kevin, L. (2008). Manajemen Pemasaran. Edisi 13 Jilid 1. Jakarta: PT Gelora Aksara Pratama.

Machfoedz, M. (2015). Kewirausahaan Metode, Manajemen, dan Implementasi. Yogyakarta: BPFE.

Masrukin. (2004). Statistik Inferensial Aplikasi Program SPSS. Kudus: Media Ilmu Press.

Masrukhin. (2009). Metode Penelitian Kuantitatif. Kudus: STAIN Kudus.

Masrukin. (2015). Statistik 1 Berbasis Computer Ekonomi Islam. Kudus: Media Ilmu Press.

Priyatno, D. (2010). Paham Analisa Statistik Data dengan SPSS. Yogyakarta: Penerbit Media Kom.

Putra, M. (2014). Pengaruh Brand Ambassador Terhadap Brand Image Serta Dampaknya Terhadap Keputusan Pembelian (Survey Pada Pengguna Line Di Asia). Jurnal Administrasi Bisnis, Vol.12 No.1.

Samosir, L. (2016). Pengaruh Penggunaan Brand Ambassador Dewi Sandra Terhadap Putusan Pembelian Kosmetik Wardah Di Kota Bandung. Jurnal Sosioteknologi. Vol.15 No.2.

Sangadji, E. \& Sopiah. (2013). Perilaku Konsumen. Yogyakarta: CV Andi Offset. Stanislaus, S., Pratiwi \& Pundani, E. (2012). Pengaruh Pengetahuan Produk Terhadap Keputusan Membeli Pada Mahasiswa Konsumen Oriflame di UNNES. Intuisis Jurnal Psikologi Ilmiah. Vol.4 No.2. 
Sterie, W. (2019). Pengaruh Brand Ambassador Dan Brand Image Terhadap Keputusan Pembelian Produk PT. Telesindo Shop Sebagai Distributor Utama Telkomsel Di Manado. Jurnal EMBA. Vol.7 No.4.

Sujarweni, V. (2015). Metodologi Penelitian Bisnis \& Ekonomi. Yogyakarta: Pustaka Barpress.

Sumarni, M., Wahyuni \& Salamah. (2006). Metodologi Penelitian Bisnis. Yogyakarta: CV Andi Offset.

Sumarwan, U. (2011). Perilaku Konsumen Teori dan Penerapannya Dalam Pemasaran. Bogor: Ghalia Indonesia.

Suzandoko, T. (2019). Pengaruh Daya Tarik Iklan Dan Citra Merek Terhadap Keputusan Pembelian Produk Luwak White Coffee Di Kota Surabaya. Tesis. Universitas Wijaya Kusuma Surabaya. Diakses Pada Link berikut ini: https://erepository.uwks.ac.id/4985/

Tandarto, R. Dharmayanti, D. (2017). Pengaruh Brand Awareness Terhadap Customer Loyalty Dengan Celebrity Endorsement Raline Shah Sebagai Variabel Intervening Top White Coffee Di Surabaya. Jurnal Strategi Pemasaran. Vol. 4. No.1

Wardhana, A \& Iba, Z. (2014). Pengaruh Penjualan Personal Terhadap Pengetahuan Produk dan Implikasinya Terhadap Keputusan Pembelian Mobil Suv Premium di Jawa Barat. Jurnal Kebangsaan. Vol.3 No.5.

Yusiana, R \& Maulida, R. (2015). "Pengaruh Gita Gutawa Sebagai Brand Ambassador Pond's Dalam Mempengaruhi Keputusan Pembelian (Studi Kasus Pada Mahasiswi Universitas Telkom Jurusan D3 Manajemen Pemasaran)". Ecodemica. Vol.3 No.1. 